SiF 2020- The $11^{\text {th }}$ International Conference on Structures in Fire

The University of Queensland, Brisbane, Australia, November 30 - December 2, 2020

\title{
MATERIAL PROPERTIES OF STRUCTURAL, HIGH STRENGTH AND VERY HIGH STRENGTH STEELS FOR POST-FIRE ASSESSMENT OF EXISTING STRUCTURES
}

\author{
Tom Molkens ${ }^{1}$, Katherine A. Cashell ${ }^{2}$, Barbara Rossi ${ }^{3,4}$
}

\begin{abstract}
This paper provides guidance on the post-fire material properties and associated safety factors for structural carbon steel which are required for the assessment and retrofitting of existing steel buildings which have suffered and survived a fire. Carbon steel can survive a fire with temperatures rising up to $600^{\circ} \mathrm{C}$, even more if the elements have been designed with sufficient overstrength. In the past decade, a number of researchers have published test data and there is more information available on the mechanical properties of steel following a fire. Nevertheless, a statistical evaluation of these results has yet to be conducted although design codes generally adopt a reliability-based approach for the analysis and assessment of buildings. To fill this gap of knowledge, a statistical evaluation of 718 tests collected from 19 peer-reviewed articles and doctoral theses. The presented results concerns low-alloy normal structural, hight strength and very high strength steels. By focusing on the effect of a fire on the mechanical properties after cooling, which is mostly related to how the coefficient of variation of their distribution increases, adjusted safety factors are proposed together with a reduced reliability index based on economic and social considerations. It is contended that by following this method, possible misunderstandings can be avoided and decisions on the salvage and rehabilitation of structures can be based on performance data and technical analysis.
\end{abstract}

Keywords: Carbon steel; post-fire; retention factor; existing buildings; statistical approach; reliability.

\section{INTRODUCTION}

This paper is concerned with the mechanical behaviour of structural carbon steel following exposure to elevated temperature and subsequent cooling. For the majority of structures that survive a fire and can be reinstated afterwards, it is necessary to ensure that they have sufficient strength and stability to survive for the rest of their projected lifetime. The influence of fire on the mechanical material characteristics of the structural elements depends on the material itself, the maximum temperature reached during the fire, the soak time at high temperature and the cooling regime. In the past, there has been considerable research effort devoted to the behaviour of structural materials following a fire, and many researchers have published performance data and even predictive formulae. However, the available data has never been assessed using a reliability-based approach. Even the most recent publications [1], [2], [3] which provide very useful information and are based on extensive literature surveys, do not include statistical data analysis.

\footnotetext{
${ }^{1} \mathrm{PhD}$ researcher, KU Leuven, Belgium

e-mail: tom.molkens@kuleuven.be, ORCID: https://orcid.org/0000-0002-3401-9047

${ }^{2}$ Dr., Brunel University London, UK

e-mail: katherine.cashell@,brunel.ac.uk, ORCID: https://orcid.org/0000-0003-2804-4542

${ }^{3}$ Prof., KU Leuven, Belgium

e-mail: barbara.rossi@,kuleuven.be, ORCID: https://orcid.org/0000-0001-6228-0309

${ }^{4}$ Prof, New College Oxford University, UK

e-mail: barbara.rossi@new.ox.ac.uk, ORCID: https://orcid.org/0000-0001-6228-0309
} 
In this context, the current paper aims to fill this gap by using the available information from the literature and conducting a reliability-based assessment which can then be used in the analysis of structures following a fire to make informed decisions on their future service life. Probabilistic-based codes require that, by preference, uncertainties should be presented based on an array of available, measured, data. Herein, a meta-analysis is used to generate more general applicable retention factors $R_{\theta}$ and to identify and quantify the most salient influential factors. The study comprises carbon steels of various strengths (Table 1), coldworked or cold-formed steel and cast or wrought irons. Currently, steel grades with a yield strength of up to $2020 \mathrm{MPa}$ are available but the very high strength grades are mainly limited in application to the automotive and aerospace sectors. This investigation is limited to grades ranging from normal strength steels to the very high strength steel grades used in structural applications, i.e. grades with a yield strength of up to a maximum value of $960 \mathrm{MPa}$.

Table 1. Names of steel grades used in this article

\begin{tabular}{llll}
\hline Name of subsets & Abbreviation & $\begin{array}{l}\text { Yield strength } \\
(\mathrm{MPa})\end{array}$ & $\begin{array}{l}\text { European reference } \\
\text { standards }\end{array}$ \\
\hline $\begin{array}{lll}\text { Normal structural steel } \\
\text { High strength structural steel }\end{array}$ & NSS & $\leq 420$ & $\begin{array}{l}\text { EN 10025-2 to 5 } \\
\text { EN 1993-1-1 Table 6.2 }\end{array}$ \\
\hline Very high strength structural steelVHSS & $>$ 420 and $\leq 700$ & $\begin{array}{l}\text { EN 10025-6 } \\
\text { EN 1993-1-1 and }-1-12\end{array}$ \\
\hline
\end{tabular}

For the mechanical properties, the main focus is given to the yield $\left(f_{y}\right)$ and tensile strength $\left(f_{u}\right)$, the ultimate strain $\left(\varepsilon_{u}\right)$ and Young's modulus $(E)$. In the design of most new buildings, the yield strength and Youngs modulus are of most significance as these are used in the strength and stability checks, as well as in the determination of deformations.

In this context, the current paper proceeds with a detailed description of the methodology which is employed for the statistical analyses. Then, the available test data is presented together with the statistical analyses to assess the post-fire mechanical properties. A methodology is proposed based by the application of a retention and additional safety factor. A more extensive explanation can be found in [4].

\section{METHODOLOGY FOR THE STATISTICAL EVALUATION OF TEST DATA}

A significant amount of test data has become available in the last decade on the mechanical behaviour of carbon steel in the post-fire condition, which provides an ideal basis for the current statistical evaluation. In this section, the procedures that are used in this article to determine the characteristic values of the mechanical properties are first discussed, followed by an overview of the experimental dataset which is used in the analysis. Then, the methodology to derive the post-fire characteristic values taking into account the variability that cannot be assigned to the post-fire situation are explained.

\subsection{Characteristic values}

This section explains the procedure for obtaining a material property value from test data, in accordance with Eurocode 0 [5] and also elsewhere [6]. The characteristic value of a single property $X_{k}$ is typically used in combination with an appropriate partial factor $\left(\gamma_{M}\right)$ from the relevant material code, to determine the design value of the property $\left(X_{d}\right)$. Reference is made to [4] for the assumptions made.

In most of the experimental programmes from which results are employed in the current work, tests on the virgin material (i.e. without heating and cooling) are also reported. These results are used as the reference value at $20^{\circ} \mathrm{C}$, namely $X_{i, a m b}$. However, in some specific cases, this information is not available in the literature and then the relation between the nominal (or code specified) yield strength $\left(f_{y, n}\right)$ and the mean 
value of the yield strength according to EN 10025, is determined in accordance with the expression given in Eq. (1) which is taken from the JCSS code of practice (2000):

$$
\mu=f_{y, n} \cdot \alpha^{\prime} \cdot \exp \left(-u \cdot V_{a m b}\right)-C
$$

where $f_{y, n}$ is the specified (or nominal) yield strength, $\alpha^{\prime}$ is the spatial position factor, exp is the natural exponential function and $u$ is a factor related to the fractile of the distribution used to describe the distance between the nominal and mean value, typically found to be in the range of -1.5 to -2.0 for EN 10025 steels. $V_{a m b}$ is the coefficient of variation at ambient conditions and $C$ is a constant which reduces the yield strength as given in mill certificate to the static yield strength; a value of $C=20 \mathrm{MPa}$ is recommended [7]. Generally, $\alpha^{\prime}$ is taken as equal to 1.05 for webs and 1.0 otherwise, to include the additional effect of the rolling direction. A value of 1.05 may be used for plates with a thickness which is less than $10 \mathrm{~mm}$.

An upper estimate for the coefficient of variation $V_{\text {test }}$ cannot be derived based on mathematical considerations and therefore some engineering judgement and professional expertise are usually needed [6]. Some guidance is provided by the JCSS code of practice and a series of coefficients of variation based on tests executed under ambient conditions $\left(V_{a m b}\right)$ are proposed, as given in Table 2 . However, as previously mentioned, these mean values and coefficients of variation are only valid for low alloy structural steel without heat treatment and which adhere to the product standard EN 10025 [8]. The values are relevant for the nominal material properties given in Table 2, where $B$ is a factor equal to 1.5 for structural carbon steel, 1.4 for low alloy steel and 1.1 for quenched and tempered steels.

Table 2. Mean values and coefficients of variation for the main material properties according to JCSS [7]

\begin{tabular}{lll}
\hline Property & Mean value $\mu$ & $V_{a m b}$ \\
\hline$f_{y}$ & $f_{y, n} \cdot \alpha^{\prime} \cdot \exp \left(-u \cdot V_{a m b}\right)-C$ & 0.07 \\
\hline$f_{u}$ & $B \cdot f_{u, n}$ & 0.04 \\
\hline$\varepsilon_{u}$ & $\varepsilon_{u, n}$ & 0.06 \\
\hline$E$ & $E_{n}=210 \mathrm{GPa}$ & 0.03 \\
\hline
\end{tabular}

According to the classification procedures for carbon steels, when a particular structural steel does not meet all of the specified mechanical conditions for a particular grade, it is downgraded to the next classification which can result in remarkable overstrength for some materials. The codified nominal values are therefore the minimum values, and many carbon steel grades exhibit considerable overstrength. That has been extensively demonstrated through a number of testing programmes (e.g. [9, 10, 11, 12]).

\subsection{Reduction of mechanical properties during fire and recovery following subsequent cooling}

A large data set comprising the results in 19 peer-reviewed journal papers and doctoral theses are included in the current study, and these are summarized in Table 3. This includes a total of 718 individual tests on with different grades of carbon steel, mostly used in structural applications, including materials from Europe (S grades), Australia (also known as S grades), China (Q grades) and North America (A grades). Each reference is characterised by a set number, its year of publication, a subset number, the corresponding steel grade, soak time during which the specimen is kept at elevated temperature and the cooling regime. A number of different cooling regimes are employed including specimens that are cooled in air (CIA), cooled in the furnace (CIF), cooled in blanket (CIB) and cooled in water (CIW). The labels LPG and Elec indicate if the specimens were heated in a liquefied petroleum gas furnace or an electrical furnace, respectively, where this information is available.

Table 3. Details of the test data

\begin{tabular}{lllllll}
\hline Authors & $\begin{array}{l}\text { Set } \\
\text { number }\end{array}$ & Year & $\begin{array}{l}\text { Subset } \\
\text { reference }\end{array}$ & $\begin{array}{l}\text { Corresponding } \\
\text { steel grade }\end{array}$ & $\begin{array}{l}\text { Soak } \\
\text { time }\end{array}$ & $\begin{array}{l}\text { Cooling } \\
\text { regime }\end{array}$ \\
\hline & & & & $(\mathrm{MPa})$ & $(\mathrm{h})$ & \\
\hline
\end{tabular}




\begin{tabular}{|c|c|c|c|c|c|c|}
\hline \multirow[t]{4}{*}{ Smith et al. [14] } & \multirow[t]{4}{*}{1} & \multirow[t]{4}{*}{1981} & 0 & \multicolumn{2}{|l|}{ Wrought } & \multirow{2}{*}{$\begin{array}{l}\text { CIA } \\
\text { CIA }\end{array}$} \\
\hline & & & 1 & S235-355JR & & \\
\hline & & & 2 & S235-355JR & 1.00 & CIA \\
\hline & & & 3 & S235-355JR & 4.00 & CIA \\
\hline \multirow[t]{2}{*}{ Outinen, [15] } & \multirow[t]{2}{*}{2} & \multirow[t]{2}{*}{2007} & $4 \mathrm{a}$ & $\mathrm{S} 355 \mathrm{~J} 2 \mathrm{H}$ & & $\mathrm{CIF}$ \\
\hline & & & $4 \mathrm{~b}$ & G350Z & & CIF \\
\hline \multirow[t]{3}{*}{ J. Lee, $[16]$} & \multirow[t]{3}{*}{3} & \multirow[t]{3}{*}{2012} & 5 & A992 $=$ S345 & 1.00 & CIA \\
\hline & & & 6 & A992 = S345 & 1.00 & CIB \\
\hline & & & 7 & $\mathrm{~A} 992=\mathrm{S} 345$ & 1.00 & CIW \\
\hline \multirow[t]{2}{*}{ Qiang et al. [17] } & \multirow[t]{2}{*}{4} & \multirow[t]{2}{*}{2012} & 8 & S460NL & 0.17 & CIA \\
\hline & & & 9 & S690QL & 0.17 & CIA \\
\hline Qiang et al. [18] & 5 & 2013 & 10 & S960QL & 0.17 & CIA \\
\hline S.P. Chiew et al. [19] & 6 & 2014 & 11 & S690RQT & 0.17 & CIA \\
\hline \multirow{2}{*}{ Gunalan et al. [20] } & \multirow[t]{2}{*}{7} & \multirow[t]{2}{*}{2014} & 12 & G300 & 1.00 & CIA \\
\hline & & & 13 & G500-550 & 1.00 & CIA \\
\hline \multirow[t]{2}{*}{ W. Wang et al. [21] } & \multirow[t]{2}{*}{8} & \multirow[t]{2}{*}{2018} & 14 & Q460 & 0.33 & CIA \\
\hline & & & 15 & Q460 & 0.33 & CIW \\
\hline \multirow[t]{2}{*}{ Lu et al. [22] } & \multirow[t]{2}{*}{9} & \multirow[t]{2}{*}{2019} & 16 & Q235-420 & 0.50 & CIA \\
\hline & & & 17 & Q235-420 & 0.50 & CIW \\
\hline \multirow[t]{2}{*}{ H.T. Li, B. Young's [23] } & \multirow[t]{2}{*}{10} & 2019 & 18 & S690 & 0.33 & $\mathrm{CIF}$ \\
\hline & & & 19 & S960 & 0.33 & CIF \\
\hline H Zhou et al. [24] & 11 & 2019 & 20 & Q690 & 0.50 & CIA \\
\hline & & & 21 & Q690 & 0.50 & CIW \\
\hline Y. Cai, B. Young's [3] & 12 & 2019 & 22 & G450-550 & 0.25 & $\mathrm{LPG} / \mathrm{CIF}$ \\
\hline & & & 23 & G450-550 & 0.25 & Elec/CIF \\
\hline X-Q Wang et al. [2] & 13 & 2020 & 24 & S690QT & $0.5-4$ & CIA \\
\hline & & & 25 & S1070QT & $0.5-4$ & CIA \\
\hline & & & 26 & S690QT & $0.5-4$ & CIF \\
\hline & & & 27 & S1070QT & $0.5-4$ & $\mathrm{CIF}$ \\
\hline & & & 28 & S690QT & $0.5-4$ & CIW \\
\hline & & & 29 & S1070QT & $0.5-4$ & CIW \\
\hline F. Azhare et al. [25] & 14 & 2017 & 30 & S1200 & & CIA \\
\hline F. Azhare et al. [26] & 15 & 2018 & 31 & S1200 & & CIW \\
\hline C. Siwei et al. [27] & 16 & 2017 & 32 & Q690 & & CIA \\
\hline Z. Chen et al. [28] & 17 & 2016 & 33 & Q460-650 & 0.33 & CIA \\
\hline & & & 34 & Q835 & 0.33 & CIA \\
\hline & & & 35 & Q460-650 & 0.33 & CIW \\
\hline & & & 36 & Q835 & 0.33 & CIW \\
\hline J. Lu et al. [29] & 18 & 2017 & 37 & G20Mn5N & 0.33 & CIA \\
\hline & & & 38 & G20Mn5QT & 0.33 & CIW \\
\hline C. Maraveas et al. [30] & 19 & 2015 & 39 & Cast & & CIA \\
\hline & & & 40 & Cast & & CIW \\
\hline
\end{tabular}


The graphs presented in section 3 represent the retention factors $R_{y, \theta}, R_{u, \theta}, R_{\varepsilon u, \theta}$ or $R_{E, \theta}$ for yield strength, ultimate strength, ultimate strain and Young's modulus, respectively, at a temperature $\theta\left({ }^{\circ} \mathrm{C}\right)$, given as the value of the considered property after a full cycle including heating to a temperature $\theta\left({ }^{\circ} \mathrm{C}\right)$ and then cooling down, normalized by its value at ambient temperature before the cycle. $R_{\theta}$ is the product of the reduction factor $k_{y, \theta}$ (or $k_{E, \theta}$ ) and a new factor named herein as the recovery factor $r_{y, \theta}\left(\right.$ or $\left.r_{E, \theta}\right)$ (i.e. $\left.r_{\theta}=R_{\theta} / k_{\theta}\right)$.

The coefficient of variation $V_{a m b}$ of the virgin material without having yet been subjected to heating and cooling is not negligible. To evaluate the modification of this coefficient after being exposed to fire, namely $V_{p o s t, \theta}$, it is assumed that both $V_{a m b}$ and $V_{\text {post }, \theta}$ are related as expressed in Eq. (2). This leads to an expression for the characteristic value of the considered property, as given in Eq. (3). Clearly, $V_{\text {post }, \theta}$ cannot be lower than zero and $V_{a m b}$ is limited to the previously chosen value of 0.07 from the JCSS code [7].

$$
\begin{gathered}
V_{\text {test }, \theta}^{2}=V_{a m b}^{2}+V_{\text {post }, \theta}^{2} \\
X_{k, \text { post }, \theta}=X_{k, \theta}=\exp \left(\mu_{\text {post }, \theta} \pm k_{n} \sqrt{\left(V_{\text {test }, \theta}^{2}-V_{a m b}^{2}\right)}\right)
\end{gathered}
$$

However, a very limited number of tests can lead to unrepresentative deviations. To avoid this, the proposed retention factor $R_{\theta}$ is adjusted by an operator in accordance with Eq. (4) where $\theta-1$ and $\theta+1$ are the preceding and following temperature intervals which has the effect of (i) forcing a decrease in the retention factor and (ii) removing the influence of outlying values, by comparing it to the averaged value of its neighbouring intervals. The maximum of both is retained.

$$
R_{\theta, i}=\min \left(R_{k, \theta-1, i} ; \operatorname{MAX}\left(R_{\theta, k, i} ; \frac{R_{k, \theta-1, i}+R_{k, \theta+1, i}}{2}\right)\right)
$$

\section{RETENTION FACTORS}

In this section, each classification of carbon steel is discussed in terms of its recovery of strength and stiffness following exposure to elevated temperature and subsequent cooling. In the following figures, the retention factor $R_{\theta}$ is presented as a solid line (with an additional subscript denoting the considered mechanical property). Additionally, the reduction factors for the yield strength $k_{y, \theta}$ and elastic modulus $k_{E, \theta}$ in accordance with Eurocode 3 Part 1-2 [31] are also presented as a dashed line.

\subsection{Normal strength structural steel}

Normal strength structural steel (NSS) is defined as steel with a yield strength between 235 and $420 \mathrm{MPa}$, as defined in Eurocode 3 Part 1-1 [32]. The set of available data is limited to 184 tests in total, from which 11 tests in ambient conditions are available. A significant degree of scatter is observed on $V_{a m b}$ which is the coefficient of variation of the virgin material and therefore it is concluded that not all steels included in these test programmes satisfy the EN 10025 product standard. The retention factors for the yield strength, ultimate tensile strength, ultimate strain and Young's modulus are presented in Figure 1.

a)

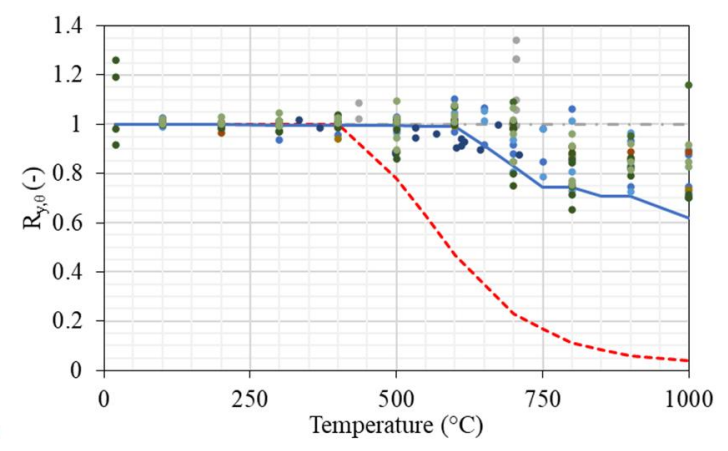

b)

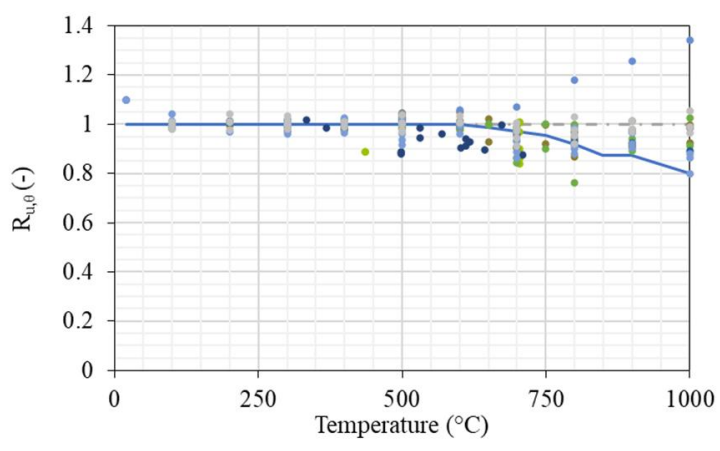


c)

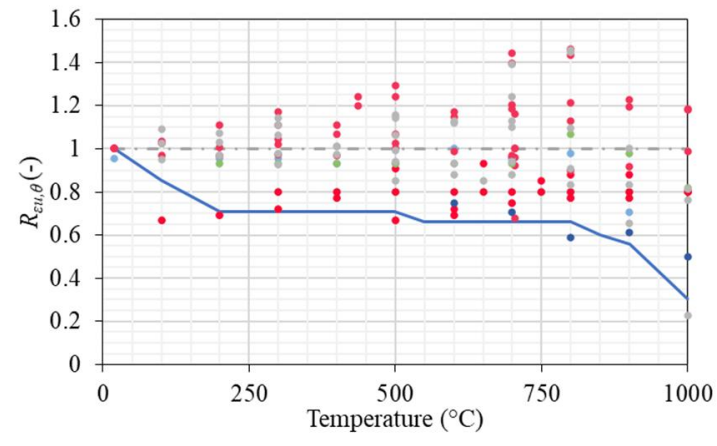

d)

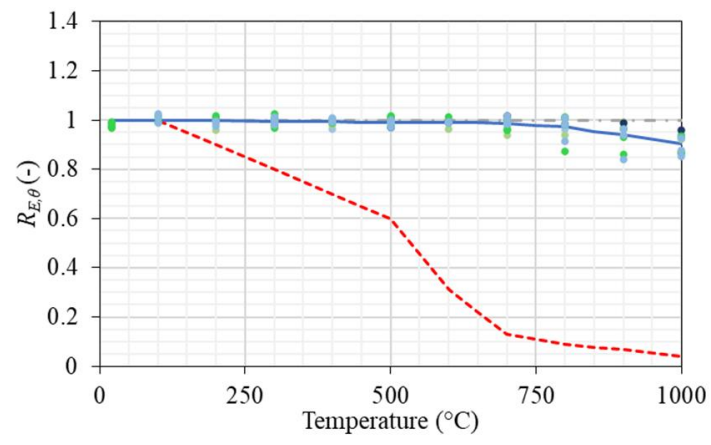

Figure 1 Summary of normal strength structural steel test results including a) yield strength, b) tensile strength, c) ultimate strain and d) Young's modulus after cooling down (dots).

With reference to the data presented in Figure 1, the following observations and conclusions are deduced:

- Yield strength: The yield strength retention factor $R_{y, \theta}$ as shown in Figure 1(a) shows a clear descending trend from approximately $600^{\circ} \mathrm{C}$ to 0.75 at $750^{\circ} \mathrm{C}$. All of the subsets show similar general behaviour including a stepwise function which can be approximated by a linear function starting from $600^{\circ} \mathrm{C}$, with a retention factor of unity, reducing to a value of 0.62 at $1000^{\circ} \mathrm{C}$.

- Ultimate strength: It is observed in Figure 1(b) that the influence of exposure to elevated temperature on the post-fire ultimate tensile strength is rather limited. The retention factor for the tensile strength $R_{u, \theta}$ remains equal to unity until about $700^{\circ} \mathrm{C}$ and then slightly decreases to a minimum value of 0.82 at $1000^{\circ} \mathrm{C}$.

- Ultimate strain: One of the ductility requirements in Eurocode 3 Part 1-1 [32] stipulates that the ratio of $f_{u} / f_{y}$ should be greater than $10 \%$. As stated before, the influence of heating and cooling is quite limited on the ultimate strength and therefore it is generally concluded that if the Eurocode 3 ductility criteria are fulfilled in the virgin material before the fire, these will be maintained even after fire and subsequent cooling.

- Young's modulus: The influence of the fire on Young's modulus is very limited. The retention factor $R_{E, \theta}$ has a value of unity until a temperature of $700^{\circ} \mathrm{C}$ and then decreases linearly to a value of 0.90 at $1000^{\circ} \mathrm{C}$.

As a general conclusion to this section on normal strength carbon steels, it can be stated that for a post-fire assessment, the verification of the resistance criteria is likely to be the most important factor. Therefore, if a structure survives a fire, it is only necessary to re-check the ultimate limit states before a structure can return to service life.

\subsection{High strength steel}

High strength steels (HSS) can be produced in a number of different ways, typically involving either heat treatment or cold-working, and therefore the influence of the temperature that is reached during a fire as well as the soak time and cooling regime are likely to be important to the post-fire mechanical properties. In the last decade, there has been a reasonable body of research published on this material including a total of 259 test results. The retention factors for the yield strength, ultimate tensile strength, ultimate strain and Young's modulus are presented in Figure 2 and are discussed hereafter. 
a)

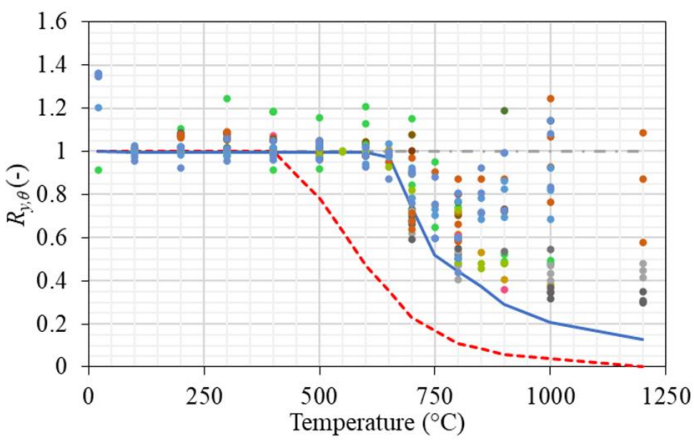

c)

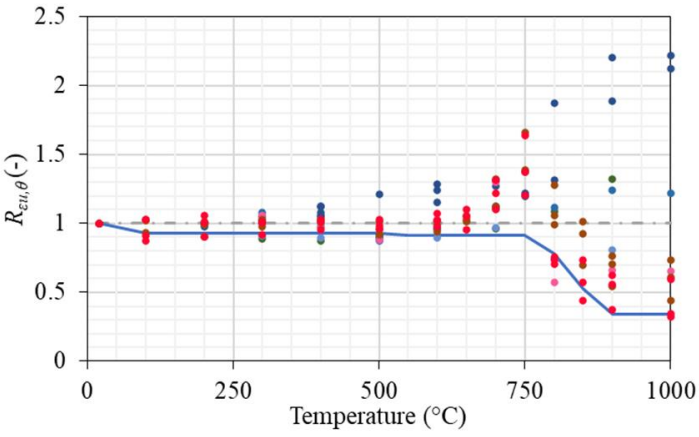

b)

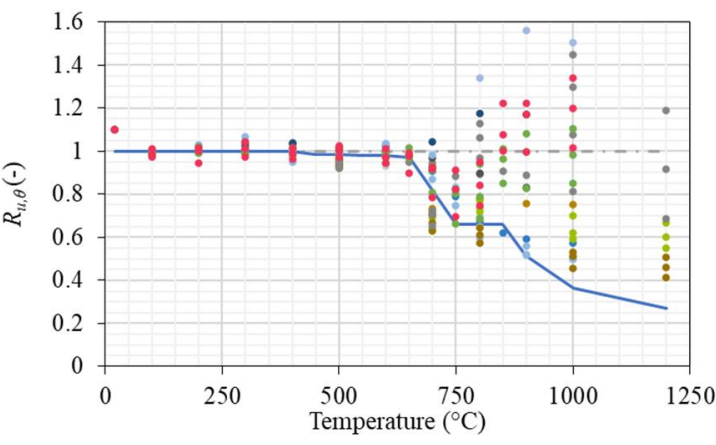

d)

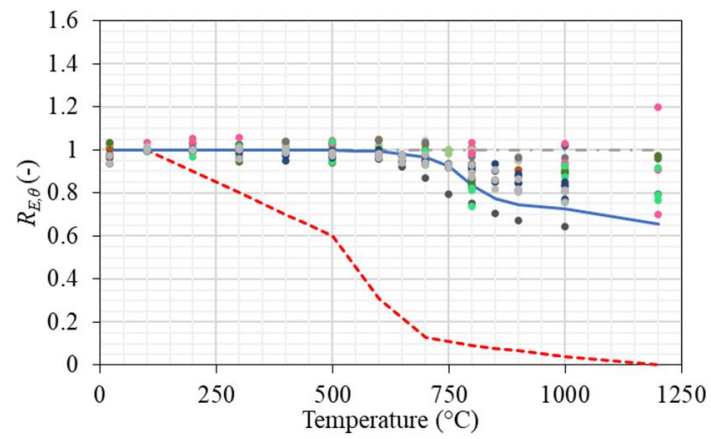

Figure 2 Summary of high strength steel test results including a) yield strength, b) tensile strength, c) ultimate strain and d) Young's modulus after cooling.

- Yield strength: As for the normal strength steels previously discussed, there is a degree of scatter for the yield strength, as shown in Figure 2(a), which is mostly as a result of the Bisalloy ${ }^{\circledR}$ samples in subsets 24, 26 and 28. These were cooled in air, furnace and in water, respectively. The yield strength retention factor $R_{y, \theta}$ follows the same trend as the reduction factor $\left(k_{y, \theta}\right)$ but with a change which is noticeably from around $650^{\circ} \mathrm{C}$.

- Ultimate strength: For the ultimate strength, between ambient and $650^{\circ} \mathrm{C}, R_{u, \theta}$ has a value of 1.0 , between $650^{\circ} \mathrm{C}$ and $750^{\circ} \mathrm{C} R_{u, \theta}$ reduces linearly to 0.66 and then remains at this value until around $850^{\circ} \mathrm{C}$ after which it again decreases to a value of 0.27 at $1200^{\circ} \mathrm{C}$.

- Ultimate strain: With reference to Figure 9(c), it is observed that the retention factor for ultimate strain $R \varepsilon_{u, \theta}$ slowly decreases to 0.91 at around $750^{\circ} \mathrm{C}$, and then drops to around 0.34 at $900^{\circ} \mathrm{C}$, and remains almost constant at this value as the temperature increases $\left(0.30\right.$ at $\left.1200^{\circ} \mathrm{C}\right)$. Subset 18 (Optim $700^{\mathrm{TM}}$ steel) also shows increased ultimate strains in terms of the retained values.

- Young's modulus: While for normal strength steel the effect of heating and subsequent cooling on the Young's modulus was very limited, a more significant reduction is observed for higher strength steels. Between ambient and $700^{\circ} \mathrm{C}, R_{E, \theta}$ has a value of 1.0 then followed by a linear reduction to 0.66 at $1200^{\circ} \mathrm{C}$. The values of subset 9 always time below the characteristic value.

\subsection{Very high strength steel}

This range of very high strength structural steel (VHSS) is covered by Eurocode 3 Part 1-12 [33] and EN 10025-6 [34]. Very high strength steels cover grades with a yield strength between $700 \mathrm{MPa}$ and $960 \mathrm{MPa}$. These are generally still quite novel in the construction sector but are growing in popularity as the attraction to lighter and more bespoke designs increases. Of the database given in Table 3, only 4 research papers include tests on these grades resulting in a total of 54 experiments, with 4 in ambient conditions. Figure 3 presents the retention factors for yield strength, tensile strength, ultimate strain and Young's modulus, based on these data. As with the high strength steels, it is noteworthy that the production route for these grades can influence their behaviour under both elevated temperature, and post-fire conditions. 
a)

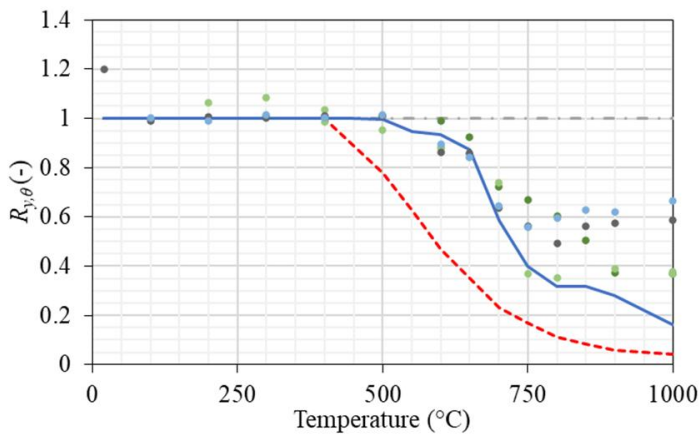

c)

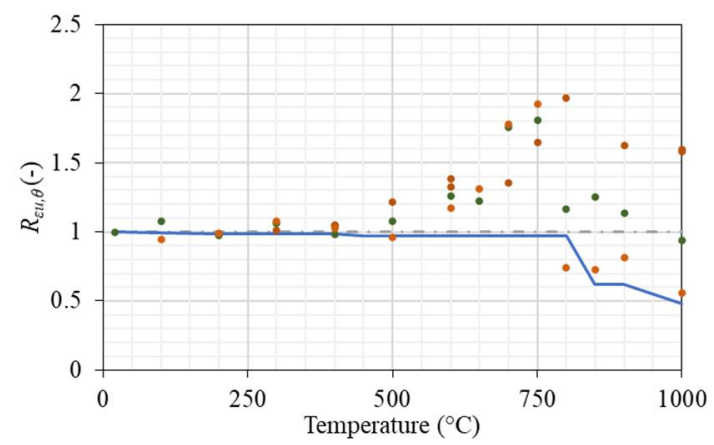

b)

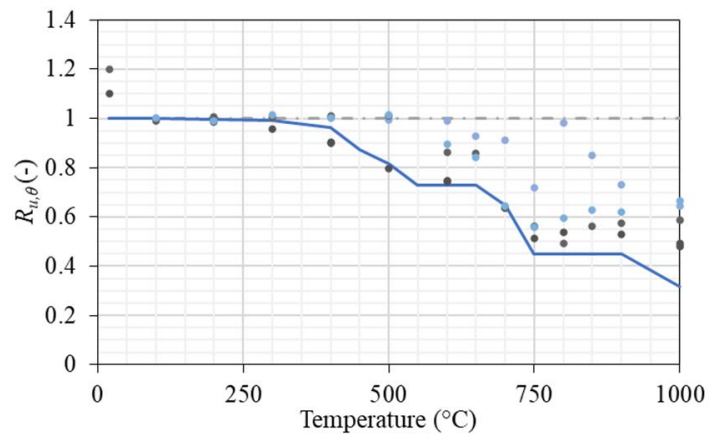

d)

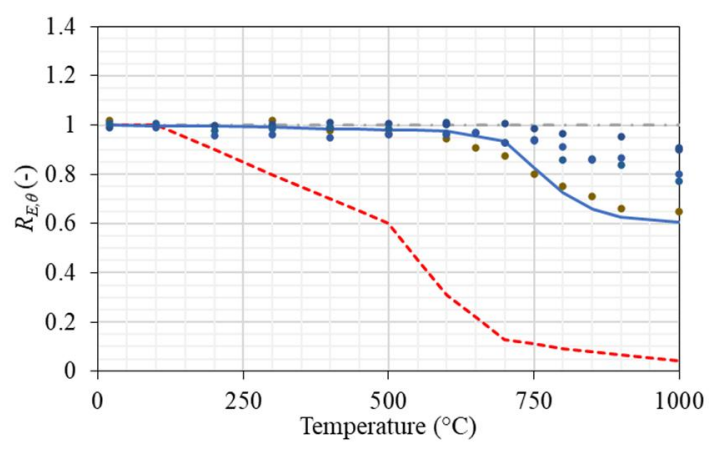

Figure 3 Summary of very high strength steel test results including a) yield strength, b) tensile strength, c) ultimate strain and d) Young's modulus after cooling.

The shape of all curves is, in general, almost the same as for the high strength steel grades. The following observations are made from the data presented in Figure 10.

- Yield strength: The yield strength follows, again, almost the same trend as the reduction factor $\left(k_{y, \theta}\right)$. The retention factor is 1.0 between ambient temperature and $500^{\circ} \mathrm{C}$, and this is followed by a linear reduction to a value of 0.84 at $650^{\circ} \mathrm{C}$ and then a further linear reduction to a value of 0.32 at $850^{\circ} \mathrm{C}$ and 0.16 at $1000^{\circ} \mathrm{C}$.

- Ultimate strength: For the ultimate strength $R_{u, \theta}$, a lower scatter is generally observed, as for the HSS-grade. After exposure to temperatures higher than $250^{\circ} \mathrm{C}$, the retention factor decreases. Starting from about $400^{\circ} \mathrm{C}$, an almost linear decrease is observed to 0.45 at $750^{\circ} \mathrm{C}$ and then up to a retention factor of 0.32 at $1000^{\circ} \mathrm{C}$.

- Ultimate strain: With reference to Figure $10(\mathrm{c})$, for the ultimate strains, after heating up to $500^{\circ} \mathrm{C}$ and then cooling, all tests deliver higher ultimate strains, the steel is relaxed and regains its initial ductility. Starting from $800^{\circ} \mathrm{C}$ however, a higher scatter is found which leads to a quick drop of the retention factor to 0.62 at $850^{\circ} \mathrm{C}$, then descending to 0.48 at $1000^{\circ} \mathrm{C}$.

- Young's modulus: The retention factor for Young's modulus exhibits a significant reduction (almost linear) from $600^{\circ} \mathrm{C}$ and has a value of 0.66 at $850^{\circ} \mathrm{C}$, as shown in Figure $10(\mathrm{~d})$. It then shows a less significant decrease to 0.61 at $1000^{\circ} \mathrm{C}$. It is noteworthy that subset 10 is largely responsible for the lower values in the higher temperature range.

\subsection{Summary of all the results}

The characteristic temperatures $\theta$ and an overview of the accompanying retention factors $R_{\theta}$ can be found in Table 4 for each material group and individual mechanical property. In the table, for each data set, the temperature/retention factor $\left(\theta\left({ }^{\circ} \mathrm{C}\right) / R_{\theta}\right)$ is provided. More detailed information can be found in [4]. 
Table 4. Proposed simplified retention factors suitable for design

\begin{tabular}{lccccccccccc}
\hline Property & $R_{y, \theta}$ & \multicolumn{3}{c}{$R_{u, \theta}$} & \multicolumn{3}{c}{$R_{\varepsilon u, \theta}$} & \multicolumn{3}{c}{$R_{E, \theta}$} \\
\hline$\theta\left({ }^{\circ} \mathrm{C}\right) / R_{\theta}$ & $\theta_{A}$ & $\theta_{B}$ & $\theta_{C}$ & $\theta_{A}$ & $\theta_{B}$ & $\theta_{C}$ & $\theta_{A}$ & $\theta_{B}$ & $\theta_{C}$ & $\theta_{A}$ & $\theta_{B}$ \\
\hline \multirow{2}{*}{ All } & $400 /$ & $750 /$ & $1200 /$ & $400 /$ & $750 /$ & $1200 /$ & $200 /$ & $750 /$ & $1200 /$ & $700 /$ & $1200 /$ \\
& 1.00 & 0.40 & 0.13 & 1.00 & 0.48 & 0.27 & 0.78 & 0.70 & 0.30 & 1.00 & 0.65 \\
\hline \multirow{2}{*}{ NSS } & $600 /$ & $750 /$ & $1000 /$ & $650 /$ & $1000 /$ & & $200 /$ & $800 /$ & $1000 /$ & $800 /$ & $1000 /$ \\
& 1.00 & 0.75 & 0.62 & 1.00 & 0.82 & - & 0.71 & 0.66 & 0.31 & 1.00 & 0.90 \\
\hline \multirow{2}{*}{ HSS } & $650 /$ & $750 /$ & $1200 /$ & $650 /$ & $750 /$ & $1200 /$ & $750 /$ & $900 /$ & $1200 /$ & $700 /$ & $1200 /$ \\
& 1.00 & 0.52 & 0.13 & 1.00 & 0.66 & 0.27 & 0.91 & 0.34 & 0.30 & 1.00 & 0.66 \\
\hline \multirow{2}{*}{ VHSS } & $600 /$ & $800 /$ & $1000 /$ & $400 /$ & $750 /$ & $1000 /$ & $800 /$ & $850 /$ & $1000 / 0$. & $600 /$ & $1000 /$ \\
& 1.00 & 0.32 & 0.16 & 1.00 & 0.45 & 0.32 & 1.00 & 0.62 & 48 & 1.00 & 0.61 \\
\hline
\end{tabular}

\section{UNCERTAINTY ASPECTS}

The recommended material safety factor $\gamma_{M 0, a m b}$ for carbon steel equals 1.0, which corresponds to a very high certainty of the material characteristics and proven overstrength. This was extensively demonstrated in a recent European project [11] and is out of the scope of this article. An increasing uncertainty has an impact on the design values used in the assessment procedure. But, since this article deals with existing structures for which the remaining lifetime might be reduced, adjustments of the reliability level are also considered.

A simple method to obtain the relevant partial factor is to divide the design value of a resistance variable by its characteristic value, as described in annexes $\mathrm{C}$ and $\mathrm{D}$ of Eurocode 0 [5]. The derivation of a material property contributing to the resistance of a material should be carried out by (i) assessing a characteristic value which is divided by a partial factor or (ii) direct determination of the design value. Thus, the appropriate safety factor will be equal to the ratio of the characteristic to the design value, as given in Eq. (5). The sensitivity factor $\alpha_{R}$ for resistance effects has a value of 0.8 in accordance with Eurocode 0 [5] and the reliability factor $\beta$ for new structures in Consequence Class 2 (CC2), is equal to 3.8 [5]. A CC2 refers to medium consequence for loss of human life, while economic, social or environmental consequences are considerable. Examples of $\mathrm{CC} 2$ are residential and office buildings, as well as public buildings with a medium consequence of failure.

$$
\gamma_{\mathrm{M} 0, \theta}=\frac{X_{\mathrm{k}, \theta}}{X_{\mathrm{d}, \theta}}=\frac{\exp \left(-1.645 \sqrt{\ln \left(\mathrm{V}_{\text {test } \left., \theta^{2}+1\right)}\right)}\right.}{\exp \left(-\alpha \sqrt{\ln \left(\mathrm{V}_{\text {test } \left., \theta^{2}+1\right)}\right)}\right.}
$$

In the previous section, Eqs. (2) and (3) gave the coefficient of variation resulting from a test $V_{\text {test, } \theta}$ as a combination of the coefficient of variation from the virgin material $\left(V_{a m b}=0.07\right)$ and the corresponding post-fire value $\left(V_{p o s t}, \theta\right)$ depending on the temperature exposure. Regarding safety factors however, the final assessment in the post-fire condition should use the product of both safety factors i.e. one factor linked to the material properties in ambient conditions $\left(\gamma_{M 0, a m b}\right)$ and another related to the post-fire conditions $\left(\gamma_{M 0, p o s t, \theta}\right)$. All of these safety factors can be derived based on Eqs. (2) and (5).

There are two challenges with this approach which need to be considered:

1. Given the chosen conservative upper value of the coefficient of variation (i.e. 0.07), the safety factor at ambient temperature $V_{a m b}$ based on the collated data is 1.10. Nevertheless, the more comprehensive recommendations of a recent European project [11] and implemented in Eurocode 3 Part 1-1 [35] recommend using a $\gamma_{M 0, a m b}$ factor of 1.0. Therefore, the product of $\gamma_{M 0, a m b}$ and $\gamma_{M 0, p o s t, \theta}$ gives $\gamma_{M 0, p o s t, \theta}$ or $\left(\gamma_{M 0, \theta}\right)$, where $\gamma_{M 0, p o s t, \theta}$ is the safety factor based on $V_{p o s t, \theta}$ with a sensitivity factor $\alpha_{R}$ of 0.8 . 
2. Due to the variation of the coefficient of variation based on tests $V_{\text {test, } \theta}$, the calculated safety factor $\gamma_{M 0, \text { test }, \theta}$ varies depending on the temperature. It is observed that the data sometimes leads to lower safety levels for steel exposed to higher temperatures which is perhaps counterintuitive. It is therefore necessary to include an operator which ensures that the safety factor does not decrease, and this is implemented using Eq. (6). The variables marked with an asterisk (*) symbol are those before the application of the operator.

$$
V_{\text {test }, i, \theta}=\operatorname{MAX}\left(V_{\text {test }, i, \theta-1}^{*} ; V_{\text {test }, i, \theta}^{*}\right)
$$

For buildings categorized in normal Consequence Class 2 [5], the reliability index $\beta$ corresponding to a probability of failure of $7.23 \cdot 10^{-5}$ equals 3.8 [6]. It has previously been shown by a number of researchers [36], [37] that there should be a distinction between new, existing and even temporary structures regarding their reliability indexes. In accordance with ISO 2394 [38] it is proposed to limit $\beta$ to a lower limit of 3.3 for an existing building in the post-fire condition, for which societal and human risks are still satisfactory [36]. Eq. (5) demonstrates that there is a direct impact of a lower $\beta$ factor on the safety factor $\gamma_{M 0, p o s t, \theta}$, and this has been calculated and is depicted in Figure 4 and summarized in Table 5. The loss in material strength is still visible through the new safety factors but its effect is decreasing.

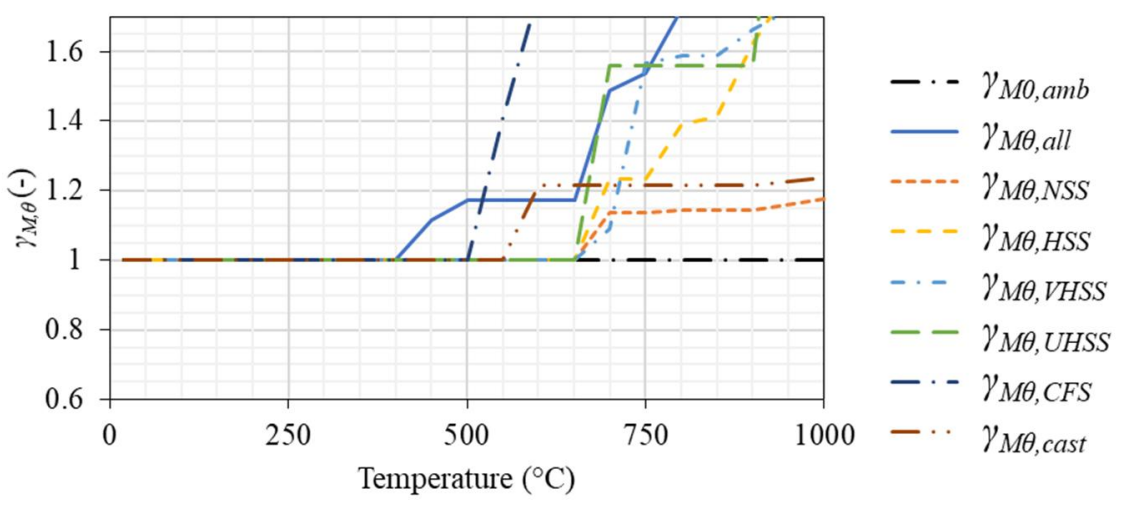

Figure 4 Summary of safety factor with a reliability index $\beta=3.3$ for the different steel grades considered in this study.

Table 5. Critical temperatures and additional safety factors for steel grades discussed in this article, with $\beta=3.3$

\begin{tabular}{|c|c|c|c|}
\hline Name of subsets & Abbreviation & $\theta\left({ }^{\circ} \mathrm{C}\right)$ & Safety factor $\gamma_{M 0, p o s t, \theta}$ \\
\hline \multirow[t]{2}{*}{ Structural steel } & \multirow[t]{2}{*}{ NSS } & $>650$ & \multirow[t]{2}{*}{1.15} \\
\hline & & $\theta_{\text {lim }}>1000$ & \\
\hline \multirow{3}{*}{ High strength structural steel } & \multirow{3}{*}{ HSS } & $>650$ & 1.25 \\
\hline & & $>750$ & $>1.40$ \\
\hline & & $>850=\theta_{\lim }$ & $>1.60$ \\
\hline \multirow{2}{*}{ Very high strength structural steel } & \multirow{2}{*}{ VHSS } & $>650$ & 1.10 \\
\hline & & $>700=\theta_{\lim }$ & $>1.60$ \\
\hline
\end{tabular}

\section{CONCLUSIONS}

This paper deals with the determination of the post-fire steel material properties and safety factors used in the assessment and retrofitting of existing steel buildings which suffered and survived a fire. It is the first reliability-based approach for the reinstatement of structures based on the available information in the literature. The data is used to derive (i) retention factors for each of the significant and characteristic material properties i.e. directly providing an easy-to-use information on how a specific property changes in value when steel is subjected to a fire and subsequently cooled down and (ii) adjusted safety factors based 
on the details analysis reflecting the increase of variation in results after being heated and cooled down. Both factors depend on the maximum temperature to which the steel is exposed.

It is shown that, for normal strength steel and cast or wrought iron, the impact of fire on the post-fire properties remains reasonable until up to temperatures of $1000^{\circ} \mathrm{C}$. For other steel grades, however, there exists a critical temperature above which reinstatement after the occurrence of a fire is economically unfeasible. In these cases, $\gamma_{\mathrm{M} 0 \text {,post, } \theta}$ is greater than 1.60 when this critical temperature is reached during the fire.

Following this work, it is recommend that the following procedure is followed in the post-fire assessment of carbon steel structures: depending on the maximum temperature reached during the fire, the retention factor is taken from Table 4 and the additional safety factor taken from Table 5.

\section{REFERENCES}

1 Y. Yu, L. Lan, F. Ding en L. Wang, „Mechanical properties of hot-rolled and cold-formed steels after exposure to elevated temperature: a review.," Construction and Building Materials, nr. 213, pp. 360-376, 2019.

2 X.-Q. Wang, Z. Tao en M. K. Hassan, „Post-fire behaviour of high-strength quenched and tempered steel under various heating conditions," Journal of Constructional Steel Research, nr. 164, 2020.

3 Y. Cai en B. Young, „Mechanical properties of thin sheet steel after exposure to high temperatures,” ThinWalled structures, nr. 142, pp. 460-475, 2019.

4 T. Molkens, K. Cashell en B. Rossi, „Post-fire mechanical properties of carbon steel and safety factors for the reinstatement of steel structures," Engineering Structures, vol. 2020, p. Under review, 2020.

5 EN 1990, Eurocode 0 Basis of structural design (consolidated version including A1:2005 and AC:2010), Brussels, Belgium: CEN, 2015.

6 H. C. Gulvanessian, J. Calgaro en M. Holicky, Designers' Guide to Eurocode: Basis of Structural Design - 2nd Ed., Croydon, UK: Thomas Telford Ltd., 2012.

7 JCSS, Probabilistic model code: Part 3 - Resistance models, Copenhagen, Denmark: DTU, 2000.

8 EN 10025, Hot rolled products of structural steels, Brussels: CEN, 2005.

9 EUR 20344, „Partial safety factors for resistance of steel elements to EC3 and EC4 - Calibration for various steel products and failure criteria," European commission, Directorate-General for Research and Innovation, Luxembourg, 2002.

10 EUR 25893, Optimizing the seismic performance of steel and steel-concrete structures by standardizing material quality control, Brussels: European commission, Directorate-General for Research and Innovation, 2013.

11 EUR 28906, „Standardization of safety assessment procedures across brittle to ductile failure modes, European commission, Directorate-General for Research and Innovation, Luxembourg, 2017.

12 L. Simões da Silva, C. Rebelo, D. Nethercot, L. Marques, R. Simões en P. Vila Real, „Statistical evaluation of the lateral-torsional buckling resistance of steel I-beams, Part 2: Variability of steel properties," Journal of Constructional Steel Research, pp. 832-849, 2009.

13 T. Molkens, K. A. Cashell, M. Malaska, F.-U. Rehman, M. Alanen en B. Rossi, „Performance of stainless steel structures following a fire," in 9th Eurosteel 2020, Sheffield, UK, 2020.

14 C. I. Smith, B. R. Kirby, D. G. Lapwood, K. J. Cole, A. P. Cunningham en R. R. Preston, „The Reinstatement of Fire Damaged Steel Framed Structures," Fire Safety Journal, vol. 4, pp. 21-62, 1981.

15 J. Outinen, Mechanical properties of structural steels at high temperatures and after cooling down, Helsinki, Finland: PhD dissertation, Helsinki University of Technology, 2007.

16 J. Lee, Elevated-Temperature Properties of ASTM A992 Steel for Structural-Fire Engineering Analysis, Austin, US: PhD dissertation, Univesity of Texas at Austin, 2012.

17 X. Qiang, F. S. Bijlaard en H. Kolstein, „Post-fire mechanical properties of high strength structural steels S460 and S690," Engineering Structures, nr. 35, pp. 1-10, 2012.

18 X. Qiang, F. S. Bijlaard en H. Kolstein, „Post-fire performance of very high strength steel S960,” Journal of Constructional Steel Research, nr. 80, pp. 235-242, 2013. 
19] S. Chiew, M. Zhao en C. Lee, „Mechanical properties of heat-treated high strength steel under fire/post-fire conditions.," Journal of Constructional Steel Research, nr. 98, pp. 12-19, 2014.

20 S. Gunalan en M. Mahendran, „Experimental investigation of post-fire mechanical properties of cold-formed steels," Thin-Walled structures, nr. 84, pp. 241-254, 2014.

21 W. Wang, T. Liu en J. Liu, „Experimental study on post-fire mechanical properties of high strength Q460 steel,” Journal of Constructional Steel Research, nr. 114, pp. 100-109, 2015.

$22 \mathrm{~J} . \mathrm{Lu}, \mathrm{H}$. Liu, Z. Chen en X. Liao, ,Experimental investigation into post-fire mechanical properties of hot-rolled and cold-formed steels," Journal of Constructional Steel Research, nr. 121, pp. 291-310, 2016.

23 H.-T. Li en B. Young, „Residual mechanical properties of high strength steels after exposure to fire,” Journal of Constructional Steel Research, nr. 148, pp. 562-571, 2018.

24 H. Zhou, W. Wang, K. Wang en L. Xu, „Mechanical properties deterioration of high strength steels after hightemperature exposure," Construction and Building Materials, nr. 199, pp. 664-675, 2019.

25 F. Azhari, A. Heidarpour, X.-L. Zhao en C. R. Hutchinson, „Post-fire mechanical response of ultra-highstrength (Grade 1200) steel under high temperatures: Linking thermal stability and microstructure," Thin-Walles Structures, nr. 119, pp. 114-125, 2017.

26 F. Azhari, A.-A. H. Apon, A. Heidarpour, X.-L. Zhao en C. R. Hutchinson, „Mechanical response of ultra-highstrength (Grade 1200) steel under extreme cooling conditions," Construction and Building Materials, nr. 175, pp. 790-803, 2018.

27 C. Siwei, J. Shaokun, G. Houzuo, C. Huixuan, L. Yifeng en L. Kang, „Mechanical and ductile fracture performances of high strength structural steel Q690 after a fire: experimental investigation," in Protect2017, Guangzhou, China, 2017.

28 Z. Chen, J. Lu, H. Liu en X. Liao, „Experimental study on the post-fire mechanical properties of high strength steel tie rods," Journal of Constructional Steel Research, nr. 121, pp. 311-329, 2016.

29 J. Lu, H. Liu, Z. Chen en L. Bisby, „Experimental investigation of the residual mechanical properties of cast steels after exposure to elevated temperature," Construction and Building Materials, nr. 143, pp. 259-271, 2017.

30 C. Maraveas, Y. Wang, T. Swailes en G. Sotiriadis, „An experimental investigation of mechanical properties of structural cast iron at elevated temperatures and after cooling down," Fire Safety Journal, nr. 71, pp. 340$352,2015$.

31 EN 1993-1-2, Eurocode 3 : Design of steel structures - Part 1.2 : General rules Structural Fire Design, Brussels, Belgium: CEN, 2005.

32 EN 1993-1-1, Eurocode 3: Design of steel structures - Part 1-1: General rules and rules for buildings (includes AC:2006, AC:2009), Brussels: CEN, 2005.

33 EN 1993-1-12, Eurocode 3 - Design of steel structures - Part 1-12: Additional rules for the extension of EN1993 up to steel grades S700 + corrigendum 2009, Brussels: CEN, 2007.

34 EN 10025-6, Hot rolled products of structural steels - Part 6: Technical delivery conditions for flat products of high yield strength structural steels in the quenched and tempered condition, Brussels: CEN, 2009.

35 EN 1993-1-1, Design of steel structures - Part 1-1: General rules and rules for buildings, Brussels, Belgium: CEN, 2005.

36 M. Sykora, D. Diamantidis, M. Holicky en K. Jung, „Target reliability levels for existing structures considering economic and societal aspects," Structure and Infrastructure Engineering, nr. 13, pp. 181-194, 2017.

37 R. Caspeele, M. Sykora, D. L. Allaix en R. Steenbergen, „The design value method and adjusted partial factor approach for existing structures," Structural Engineering International, vol. 23, nr. (4), pp. 386-393, 2013.

38 ISO 2394, General principles on reliability for structures, Geneva: International standard organization, 2015. 